\title{
Small molecule inhibitors of Apaf-1-related caspase- 3/-9 activation that control mitochondrial-dependent apoptosis
}

G Malet ${ }^{1}$, AG Martín ${ }^{2,3}$, M Orzáez ${ }^{3}$, MJ Vicent ${ }^{3}$, I Masip ${ }^{4}$, G Sanclimens ${ }^{4}$, A Ferrer-Montiel ${ }^{5}$, I Mingarro ${ }^{1}$, A Messeguer ${ }^{4}$, HO Fearnhead ${ }^{2}$ and E Pérez-Payá ${ }^{\star, 3,6}$

${ }^{1}$ Department of Biochemistry and Molecular Biology, Universitat de València, E-46100 Burjassot, València, Spain

2 Apoptosis Section, Regulation of Cell Growth Laboratory, NCl, National Institutes of Health, Frederick, MD 21702, USA

3 Department of Medicinal Chemistry, Centro de Investigación Príncipe Felipe, E-46013 València, Spain

${ }^{4}$ Department of Biological Organic Chemistry, IIQAB (CSIC), E-08034 Barcelona, Spain

5 Instituto de Biología Molecular y Celular, Universidad Miguel Hernández, 03202 Elx Alacant, Spain

${ }^{6}$ Consejo Superior de Investigaciones Científicas (CSIC), E-46013 València, Spain

* Corresponding author: E Pérez-Payá, Centro de Investigación Príncipe Felipe and CSIC, Avda. Autopista del Saler, 16, E-46013 Valencia, Spain.

Tel: + 34-963289680; Fax: + 34-963289701; E-mail: eperez@ ochoa.fib.es

Received 27.5.05; revised 25.10.05; accepted 02.11.05; published online 09.12.05 Edited by $Y$ Tsujimoto

\section{Abstract}

Apoptosis is a biological process relevant to human disease states that is strongly regulated through protein-protein complex formation. These complexes represent interesting points of chemical intervention for the development of molecules that could modulate cellular apoptosis. The apoptosome is a holoenzyme multiprotein complex formed by cytochrome c-activated Apaf-1 (apoptotic proteaseactivating factor), dATP and procaspase-9 that link mitochondria disfunction with activation of the effector caspases and in turn is of interest for the development of apoptotic modulators. In the present study we describe the identification of compounds that inhibit the apoptosome-mediated activation of procaspase-9 from the screening of a diversityoriented chemical library. The active compounds rescued from the library were chemically optimised to obtain molecules that bind to both recombinant and human endogenous Apaf-1 in a cytochrome c-noncompetitive mechanism that inhibits the recruitment of procaspase- 9 by the apoptosome. These newly identified Apaf-1 ligands decrease the apoptotic phenotype in mitochondrial-mediated models of cellular apoptosis.

Cell Death and Differentiation (2006) 13, 1523-1532. doi:10.1038/sj.cdd.4401828; published online 9 December 2005

Keywords: apoptosis; apoptosome; Apaf-1; caspasa-3; caspasa-9; combinatorial libraries; inhibitor; molecular recognition; peptoid; protein-protein interactions; small molecule

\begin{abstract}
Abbreviations: Apaf-1, apoptotic protease-activating factor; DEVDase, hydrolysis of Ac-DEVD-afc; DTT, dithiothreitol; FCS, fetal-calf serum; MEFs, mouse embryo fibroblasts; MMP, mitochondrial membrane potential; MTT, 3-(4,5-dimethylthiazol-2-yl)-2,5-diphenyltetrazolium bromide; Ni-NTA, $\left(\mathrm{Ni}^{2+}\right.$-nitrilotriacetate)-agarose; peptoid f1a, 5'-6 carboxyfluorescein-labelled peptoid 1a; PBS, phosphate-buffered saline; PGA, poly-(L-glutamic acid); rApaf-1, recombinant Apaf-1
\end{abstract}

\section{Introduction}

Protein-protein interactions play a critical role in almost all cellular and biological processes. Consequently, the interactions between proteins represent points of chemical intervention for therapeutic gain in the biological processes associated with disease. Apoptosis is an interesting biological process because of its importance in a wide variety of biological systems, including normal cell turnover, the immune system and embryonic development and its association with different diseases. Inappropriate apoptosis is involved in many human pathologies, including neurodegenerative diseases such as Alzheimer's and Huntington's, ischaemia, autoimmune disorders and several forms of cancer. ${ }^{1}$ Diverse apoptotic stimuli, including activation of cell surface death receptors, anticancer agents, irradiation, lack of survival factors, and ischaemia (reviewed in Strasser et $\mathrm{al}^{2}$ ) induce signalling cascades that all activate a family of cysteine aspartyl proteases called caspases. It is these proteases that execute the apoptotic process. Effector caspases (e.g. caspases-3 and -7) are responsible for the disassembly of cellular components while initiator caspases (e.g. caspases-8, -9 and -10) are responsible for activation of the effector caspases. While different apoptotic stimuli activate different initiators, these initiators activate a common set of effector caspases. Because of the critical consequences of apoptosis malfunctioning, the activation of caspases is scrupulously controlled. Some apoptotic signals activate the mitochondria-mediated or intrinsic pathway that utilises caspase -9 as its initiator. Caspase- 9 activation is triggered by the release to the cytosol of proapoptotic proteins from the mitochondrial inter-membrane space, in particular cytochrome $c$ and Smac/Diablo. ${ }^{3,4}$ The formation of the macromolecular complex named apoptosome is a key event in this pathway. The apoptosome is a holoenzyme multiprotein complex formed by cytochrome $c$-activated Apaf-1 (apoptotic protease-activating factor), dATP and procaspase-9. ${ }^{5-8}$ In this macromolecular complex, apoptosomeassociated caspase- 9 is activated and then, in turn, activate effector caspases. To identify molecules that could ameliorate disease-associated apoptosis, drug discovery 
efforts have initially targeted caspase activity ${ }^{9,10}$ rather than activation. Nevertheless, protein-protein interactions upstream of caspase activation can be also relevant points of intervention for the development of modulators of apoptosis pathways. In particular, recent data propose the formation of the apoptosome as an interesting target for the development of apoptotic modulators. ${ }^{11-14}$ In the absence of detailed structural information, the conventional methods used for the identification of modulators of the apoptosome have been based in indirect measurements of the cytochrome $c$ - and dATP-induced activation of caspase3-like activity on defined cytosolic extracts. ${ }^{15,16}$ Using this methodology Lademann et al. $^{15}$ have identified inhibitors of the apoptosome through the screening of small molecules using cytosolic extracts of selected cells while Nguyen et al. ${ }^{16}$ reported the identification of activators.

We are currently engaged in a discovery program employing an in vitro reconstituted active apoptosome assembled from its recombinant constituent proteins. Here we describe the identification of compounds that inhibit the apoptosomemediated activation of procaspase- 9 from the screening of a diversity-oriented chemical library of $\mathrm{N}$-alkylglycines. The active compounds rescued from the library were chemically optimised to obtain molecules that bind to both recombinant and human endogenous Apaf-1 and decrease the apoptotic phenotype in mitochondrial-mediated models of cellular apoptosis.

\section{Results}

\section{Screening of a positional scanning library of peptoids as a source for apoptosome inhibitors}

Oligomers of $\mathrm{N}$-alkylglycines, also known as peptoids, constitute a family of non-natural molecules attractive for the drug discovery process due to their broad variety of biological activities and to the proteolytic stability that they exhibit. ${ }^{17,18}$ We have early designed a positional scanning diversityoriented combinatorial library of trimers of $\mathrm{N}$-alkylglycines ${ }^{19}$ that allowed the identification of lead compounds in different biological assays. ${ }^{20-22}$ We have now modified the diversity of the library to generate an optimised version of the original library in terms of composition and concentration of the different components. ${ }^{23}$ The library consists in 52 controlled mixtures and a total of 5120 compounds. The mixtures were screened for their ability to prevent the apoptosome-dependent activation of procaspase-9. The apoptosome was assembled in vitro by incubating rApaf-1, cytochrome $c$, dATP and $\left[{ }^{35}\right.$ S]Met procaspase- 9 (see Materials and Methods section and Supplementary information). Samples were subjected to SDS-PAGE and caspase-9 processing subsequently visualised by phospho-imaging. Defined mixtures from the library inhibited the apoptosome-dependent activation and allowed the deconvolution process and identification of four discrete compounds (peptoids 1-4, Figure 1a) that inhibited the apoptosome-dependent activation of a

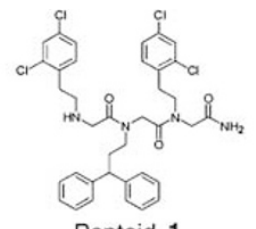

Peptoid 1

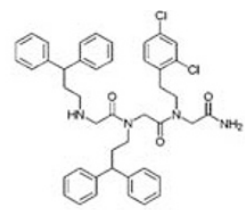

Peptoid 2

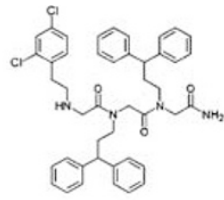

Peptoid 3

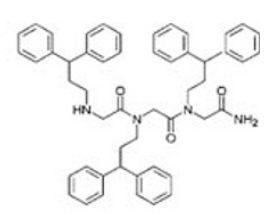

Peptoid 4 b

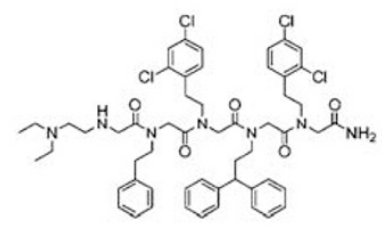

Peptoid 1a

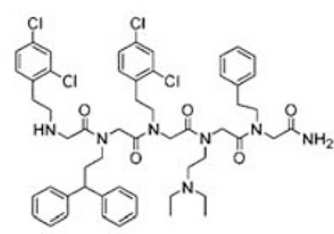

Peptoid 1b

C

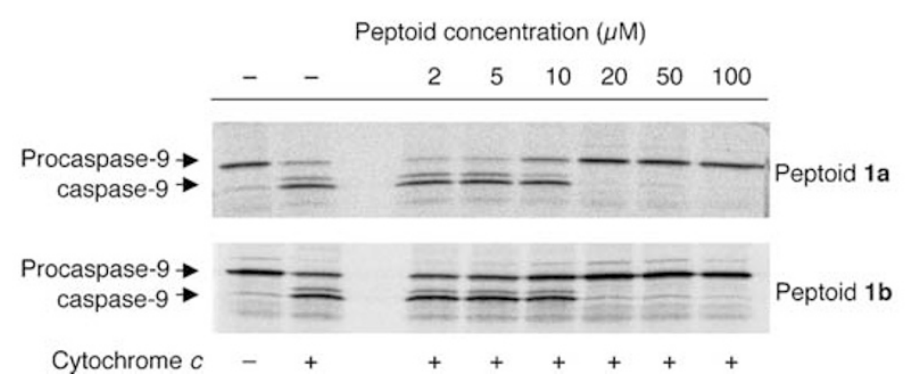

Figure 1 Peptoids rescued from the library inhibit apoptosome dependent procaspase-9 processing in an in vitro assay. (a) Chemical structures of peptoids 1 to 4 rescued from the screening of the library of $N$-alkylglycines. (b) Chemical structures of peptoids $1 \mathbf{a}$ and $\mathbf{1 b}$. (c) Peptoid $1 \mathbf{a}$ (upper panel) and peptoid $1 \mathbf{b}$ (lower panel) were evaluated in a concentration-dependent manner for their capacity to inhibit apoptosome-dependent activation of procaspase-9 
procaspase- 9 to different extent in a concentration-dependent manner. A peptoid from our stock collection was used as negative control. The most potent inhibitor was peptoid $\mathbf{1}$. However, probably due to the overall intrinsic hydrophobicity of all four compounds, problems of reproducibility were encountered from batch-to-batch solubilised peptoids. Then we decided to generate more soluble analogues of peptoid 1. Previous experience in the design of bioactive peptides ${ }^{24,25}$ suggested that the presence of positively charged side chains at both $\mathrm{N}$ - and $\mathrm{C}$-terminus ends of peptides increased the overall peptide solubility without modifying their conformational or biological properties. Furthermore, in our laboratory, we have used an $\mathrm{N}$-substituted alkylglycine hexamer composed by residues containing a simple benzene ring or a tertiary amino moiety attached to a bioactive hexapeptide sequence to increase both aqueous solubility and cellmembrane permeability (unpublished results). With these precedents, peptoids $\mathbf{1 a}$ and $\mathbf{1 b}$ containing two additional $\mathrm{N}$-alkylamine residues at the $\mathrm{N}$ - or $\mathrm{C}$-terminus ends, respectively, were synthesised (Figure $1 \mathrm{~b}$ ) and their in vitro activity tested. These two peptoids inhibited the apoptosomemediated procaspase- 9 activation with an excellent batch-tobatch reproducibility and an $\mathrm{IC}_{50}$ close to $10 \mu \mathrm{M}$ (Figure 1c). Preliminary structure-activity relationship analysis on the peptoid 1 family suggested that the dichlorophenylethylamino moiety was important for activity. Peptoid 1d, derived from peptoid $\mathbf{1 b}$ with a deletion at the $\mathrm{N}$-terminus of an $\mathrm{N}$-dichlorophenylethylglycine, had a reduced inhibitory activity when compare to peptoid $\mathbf{1 b}$ (results not shown) in the in vitro apoptosome activity assay.

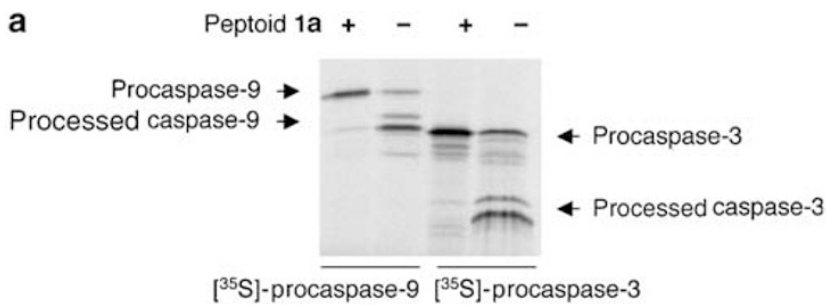

b

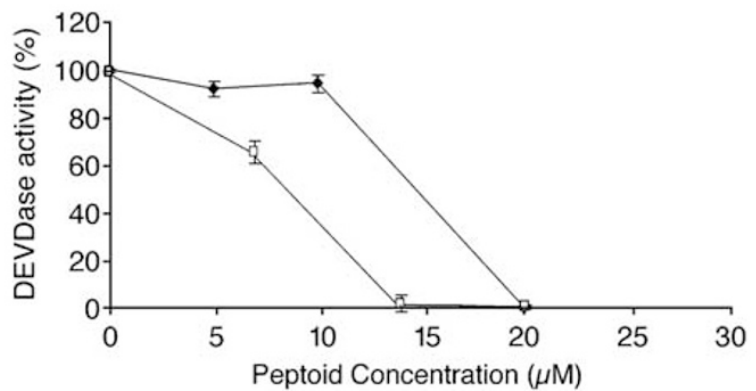

Figure 2 Peptoid 1a inhibits apoptosome mediated caspase-3 activation. (a) Left panel. In vitro translated ${ }^{35}$ SJMet procaspase- 9 and procaspase- 3 were incubated in the presence of rApaf-1, cytochrome $c$ and in the presence or absence of peptoid $1 \mathrm{a}(20 \mu \mathrm{M})$. Right panel. In vitro translated procaspase-9 and $\left[{ }^{35}\right.$ S]Met procaspase- 3 were incubated in the presence of rApaf-1, cytochrome $c$ and in the presence or absence of peptoid 1a. (b) DEVDase activity on FT extracts was measured in the presence or absence of increasing concentrations of both peptoid $1 \mathrm{a}(\square)$ and peptoid $1 \mathrm{~b}(\bullet)$. rApaf-1 was incubated with peptoids at $30^{\circ} \mathrm{C}$ for $30 \mathrm{~min}$ and combined with a $5 \mu \mathrm{l}$ aliquot of FT extract. DEVDase activity was measured and referred to a positive control (100\% activity)
Peptoid 1a inhibited caspase-3 processing (Figure 2a) when the apoptosome activity was followed in the presence of rApaf-1, cytochrome $c$, dATP, and both in vitro translated $\left[{ }^{35}\right.$ S]Met procaspase- 9 and -3 (see Materials and Methods section). Furthermore, we tested apoptosome-dependent caspase- 3 activation by adding rApaf- 1 to an Apaf- 1 free cell extract $^{14}$ and measuring Ac-DEVD-afc hydrolysis (DEVDase activity; Figure 2b). This confirmed a dose-dependent inhibitory activity of the peptoids in this assay that correlated with their ability to inhibit apoptosome formation (Figure 1c). It is worth mentioning that a recombinant caspase 3 activity in vitro assay (Calbiochem) showed that the inhibitory properties of peptoid 1a were not due to a direct inhibition of caspase 3 (data not shown).

\section{Peptoid 1a directly binds to rApaf-1 and induces a nonactive apoptosome complex}

The apoptosome is assembled when seven Apaf-1:cytochrome $c$ heterodimers oligomerise to form a 'wheel' structure that has the ability to recruit procaspase-9. .,26-28 $^{\text {To initially }}$ characterise the binding site of the peptoids to the apoptosome, we synthesised a fluorescent analogue of peptoid 1a (peptoid f1a). Peptoid f1a bound to rApaf-1, but not to cytochrome $c$ and other control proteins (Figure 3A), with dissociation constant $\left(K_{\mathrm{d}}\right) 57 \pm 12 \mathrm{nM}$ as determined in a fluorescence polarisation assay. Nevertheless, the binding constant value contrasted with the concentration of peptoid $\mathbf{1 a}$ that was needed to inhibit $50 \%$ of caspase activity in our assays $\left(\mathrm{IC}_{50} \sim 10 \mu \mathrm{M}\right.$, Figure $\left.1 \mathrm{c}\right)$. A putative explanation to reconcile these data is that the reticulocyte lysate used to in vitro translate procaspase- 9 contained components that diminished the effective concentration of peptoid $\mathbf{1 a}$. Next, we evaluated whether or not peptoid 1a inhibits cytochrome $c$ binding to rApaf-1. In the fluorescence polarisation assay, the dissociation constant for the interaction rApaf-1/peptoid f1a was not influenced by the presence of up to five-fold molar excess of cytochrome $c$ (not shown). Furthermore, we also performed the in vitro apoptosome reconstitution assay in the presence of increasing concentrations of cytochrome $c$. Regardless of the concentration of cytochrome $c$ used, peptoid 1a exerted its inhibitory activity on apoptosome-dependent procaspase- 9 cleavage (Figure 3B). These results suggest that peptoid 1a directly binds to rApaf-1 in a binding site different from that of the cytochrome $c$ recruitment site and induces a conformational change in Apaf-1 that precludes procaspase-9 processing. In principle, the peptoid may have prevented any of the steps leading to caspase- 9 activation including Apaf-1 oligomerisation and caspase recruitment. ${ }^{26}$ To test which step of caspase activation was blocked, rApaf-1 was incubated in the presence and absence of peptoid 1a, cytochrome $c$ and dATP and the ability to activate caspases from cell lysates was evaluated before and after chromatography on Superose-6 $\mathrm{H}-\mathrm{R}$ analytical gel filtration column. Before gel filtration (Figure 3C; sample $\boldsymbol{a}$ is a control only containing FT extract), the sample containing rApaf-1, cytochrome $c$ and dATP (sample $\boldsymbol{b}$ ) was able to activate caspases and this was inhibited by peptoid 1a 


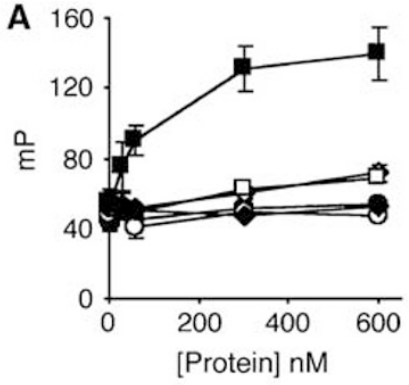

B

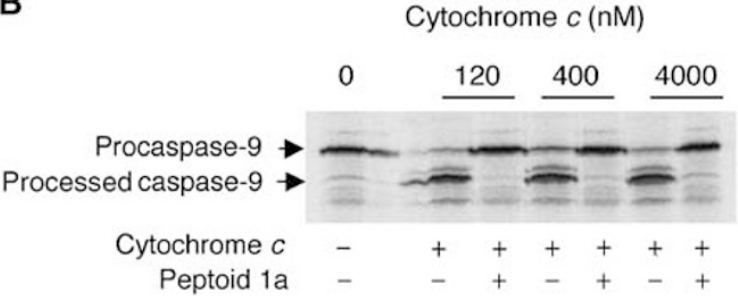

C

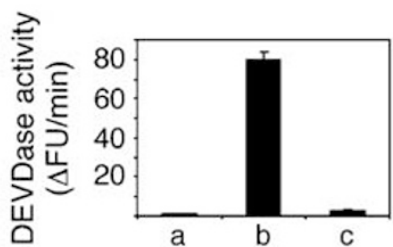

D

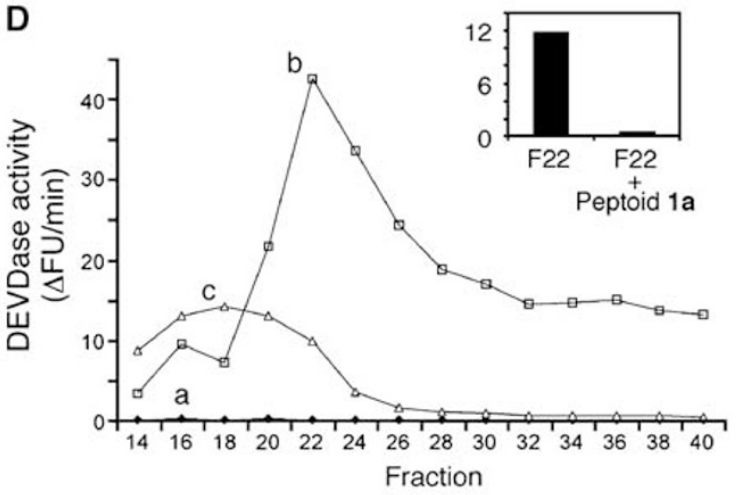

E

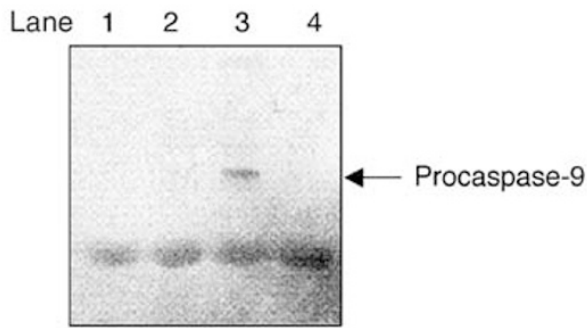

Figure 3 Peptoid 1a binds to and induces a conformational change on rApaf-1. (A) A $60 \mathrm{nM}$ solution of peptoid f1a in buffer A was titrated with increasing concentrations of rApaf-1 $(\mathbf{\square})$, cytochrome $c(\diamond)$, RNAase A $(O)$, synthetic tetramerisation domain of p53 $(\mathbf{O})$, aldolase $(\square)$, catalase $(\diamond)$ and fluorescence polarization was measured at $30^{\circ} \mathrm{C}$. The data (mean S.D.; $n=3$ ) were recorded in millipolarization units $(\mathrm{mP}$ ) and adjusted to a two-state binding model. (B) Apoptosome-dependent activation of procaspase- 9 was followed by incubating in vitro transcribed-translated $\left[{ }^{35}\right.$ S]Met procaspase-9 and rApaf- 1 in the presence or absence of peptoid $1 \mathrm{a}(20 \mu \mathrm{M})$ at different concentrations of cytochrome $c$. (C) Three different sample preparations of rApaf-1 were used in conjunction with FT aliquots from cell lysates (see Material and Methods section) to determine caspase processing activity by measuring DEVDase activity. Sample a, contains rApaf-1 but no cytochrome $c$; sample $\mathbf{b}$ and sample $\mathbf{c}$ contain rApaf-1, cytochrome $c$ and dATP in the absence (b) or in the presence (c) of peptoid $1 \mathbf{a}(50 \mu \mathrm{M})$ that was incubated with rApaf- 1 for $30 \mathrm{~min}$ at $30^{\circ} \mathrm{C}$ prior addition to the FT aliquot. (D) Samples $\mathbf{a}, \mathbf{b}$ and $\mathbf{c}$ were applied to Superose $6 \mathrm{H}-\mathrm{R}$ column and elution fractions were used in conjunction with FT aliquots to determine DEVDase activity (diamonds, filled squares and white triangles denote activity for fractions from samples $\mathbf{a}, \mathbf{b}$ and $\mathbf{c}$, respectively). Inset. The DEVDase activity of aliquots of fraction 22 was also determined in the absence (F22) or in the presence of peptoid 1a (F22 + peptoid 1a). (E) rApaf-1-mediated pulldown of procaspase-9. Aliquots from samples $\mathbf{a}, \mathbf{b}$ and $\mathbf{c}$ were combined with a $5 \mu$ laliquot of an in vitro translation reaction of noncleavable $\left[{ }^{35}\right.$ S]Met procaspase-9 (procaspase-9 mutant D315/330A) and mixed with $\mathrm{Ni}^{2+}{ }_{-} \mathrm{NTA}$-agarose beads. After centrifugation, the material eluted from the beads was subjected to SDS-PAGE. Lane 1 , control no rApaf-1; lane $2-4$, recovery from samples $\mathbf{a}, \mathbf{b}$ and $\mathbf{c}$, respectively

(sample $\boldsymbol{c}$ ). Aliquots from samples $\boldsymbol{a}, \boldsymbol{b}$ and $\boldsymbol{c}$ were subjected to gel filtration chromatography and the DEVDase activity of collected fractions was evaluated (Figure 3D). The elution profile of sample $\boldsymbol{b}$ showed a major peak, with DEVDase activity, centred on fraction 22 that corresponds to a size of $\sim 700 \mathrm{kDa}$. This is consistent with the reported size of the active apopotosome. ${ }^{29,30}$ The DEVDase activity of fraction 22 was inhibited in the presence of peptoid 1a (inset in Figure 3D). However, the elution profile of sample $c$ showed a very low DEVDase activity around fraction 18 and we could not detect the presence of Apaf-1 in this fraction by immunoblot (not shown). These data suggest that in the presence of cytochrome $c$ and dATP, monomeric rApaf-1 could be induced to form a $\sim 700 \mathrm{kDa}$ active complex. Peptoid 1a could bind to monomeric or complexed rApaf-1 and induce a conformational change in $\mathrm{rApaf}-1$ rendering a poorly active conformation. To determine whether or not peptoid 1ainhibited apoptosome is capable of procaspase-9 recruitment, we performed a rApaf-1-mediated pull-down experiment (Figure 3E). Noncleavable $\left[{ }^{35} \mathrm{~S}\right]$ Met procaspase-9 was coprecipitated with rApaf-1 in the presence of cytochrome $c$ and dATP (lane 3, Figure 3E). However, the presence of peptoid 1a precludes recruitment of procaspase- 9 by the apoptosome (lane 4, Figure 3E). 


\section{Peptoid 1a inhibits human endogenous Apaf-1 and decrease apoptotic phenotype in cellular models of drug induced apoptosis}

Next, we tested whether peptoid 1a is able to inhibit cellular Apaf-1 as it inhibits rApaf-1. We used a cell-free system obtained from 293 cells. ${ }^{31}$ This extract was fractioned on a Q-sepharose column that, as mentioned before, results in a fraction (named F1) enriched in endogenous Apaf-1 and a flow-through fraction (named FT) that contains cytochrome $c$ and caspases, thus separating the components needed for caspase-9/-3 activation. These two fractions could effectively reconstitute caspase activation. However, when the F1 fraction was preincubated with peptoid 1a and then mixed with FT, there was no detectable caspase activation (Figure 4). These results indicate that peptoid 1a inhibits both, endogenous cellular Apaf-1 and rApaf-1.

Initial examination of the ability to inhibit apoptosis in intact cells, suggested that peptoid 1a suffers of low capacity to cross cellular membranes. In order to overcome this difficulty, new series of peptoid $\mathbf{1}$ analogues were designed covering three different approaches that could facilitate cellular drug internalisation (Figure 5a). First, we synthesised a hybrid peptide/peptoid molecule where peptoid 1 was fused to the well-characterised cell carrier peptide penetratin, derived from the sequence of the Drosophila transcription factor antennapedia. $^{32,33}$ Secondly, we synthesised the analogue cyclopeptoid $\mathbf{1}$, a conformationally constrained peptoid $\mathbf{1}$ mimetic. Third, a poly-(L-glutamic acid) (PGA) peptoid 1 conjugate, PGA-GG-peptoid 1, was also synthesised to explore the endocytic internalisation approach. ${ }^{34}$ Penetratin-GG-peptoid $\mathbf{1}$ and cyclo-peptoid $\mathbf{1}$ were active as inhibitors in the cell free assays (data not shown), showed lowered cell toxicity and allowed their use in cell based assay models. Cell-free experiments are no suitable as preliminary activity test for prodrugs, such as the derivative PGA-GG peptoid 1, because polymer conjugates adopt a unimolecular micelle 3D structure in solution hiding the active hydrophobic drug at the core..$^{35}$ To investigate whether these molecules would inhibit mitochondrial mediated apoptosis, assays with: U937 human histiocytic

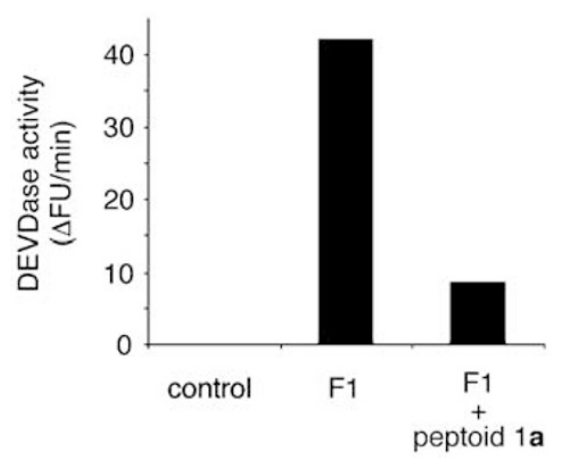

Figure 4 Peptoid 1a inhibits human endogenous Apaf-1 mediated activation of caspases. A measure of $3 \mu \mathrm{l}$ aliquots of $\mathrm{F} 1$ extract were incubated at $30^{\circ} \mathrm{C}$ by $15 \mathrm{~min}$ in the presence or absence of peptoid $1 \mathrm{a}(50 \mu \mathrm{M})$ and then combined with a 5- $\mu$ aliquot of FT extract, $1 \mathrm{mM}$ dATP and further incubated at $37^{\circ} \mathrm{C}$ by $30 \mathrm{~min}$. DEVDase activity was measured for each of the two samples ( $F 1$ and $\mathrm{F} 1+$ peptoid 1a) and for a negative control buffer $\mathrm{A}$ lymphoma cells challenged with doxorubicin; Saos-2 human osteosarcoma cells with conditional expression of the proapoptotic protein Bax (Saos Bax tet-ON) and mouse embryo fibroblasts (MEFs) challenged with TNF- $\alpha$ were performed in culture. In the first cell-based model, doxorubicin induces apoptosis through DNA damage that is transduced to the mitochondria disturbing the mitochondrial membrane potential (MMP) and activating executioner caspases through involvement of the apoptosome. After $12 \mathrm{~h}$, doxorubicin treated cells demonstrated staining for annexin V-PE (that specifically binds to exposed phosphatidylserine) and lost of MMP (Figure $5 b$ and $c$ ). When cells were treated with doxorubicin in the presence of penetratin-GG-peptoid 1 or of cyclo-peptoid 1, the extent of doxorubicin-induced apoptosis was remarkably diminished as determined by the lowered percentage of cells with apoptotic phenotype (Figure $5 b$ and c). In the Saos-2 cell model, apoptosis is induced by the conditional expression of Bax through the tet-ON system (Clontech). Bax is a proapoptotic member of the Bcl-2 family that induces apoptosis through liberation of cytochrome $c$ from the mitochondria, ${ }^{36}$ thus activation of apoptosis solely relies in the mitochondrial pathway. In this model, PGA-GGpeptoid 1 showed a dose- and time-dependent prevention of cell-viability lost induced by expression of Bax as measured in 3-(4,5-dimethylthiazol-2-yl)-2,5-diphenyltetrazolium bromide (MTT) assays (data not shown). In addition and more relevant for the present study, a time-dependent (up to $72 \mathrm{~h}$ ) inhibition of caspase-3 activity was observed (Figure $5 d$ ) consistent with PGA-GG-peptoid 1 inhibition of Apaf-1 dependent apoptosis. The time dependence of the process is due to the lysosomotropic intracellular drug delivery mechanism associated to PGA-GG-peptoid $1 .^{34}$ In order to assess specificity of peptoid 1 for the mitochondrial pathway, apoptosis was induced by TNF $\alpha$ in MEFs. This is a type I system where apoptosis is induced by ligation of death receptors of the TNF family without the involvement of cytochrome $c$ liberation from the mitochondria. None of the modified forms of peptoid 1 used had any detectable inhibitory effect on TNF $\alpha$ induced apoptosis (data not shown), indicating that only the mitochondrial pathway of caspase activation is inhibited by peptoid $\mathbf{1}$.

\section{Discussion}

Within the last decade enormous progress has been made in the understanding of the molecular basis of apoptosis paralleled with an increased interest in the potential clinical applications of molecules that could modulate the key events of the apoptotic machinery. Due to the unwanted activation of the apoptosis program in several diseases, the initial efforts were directed towards the inhibition of caspases. Caspase-3 has been one of the more intensely studied enzymes in terms of potential target in neurodegenerative diseases and stroke. ${ }^{1,9,37}$ However, as it is true for other cellular pathways of relevance in therapy for a potential therapeutic intervention, more than one isolated protein has to be targeted to increase the therapeutic value. Accordingly, the identification of new potential drugs for the treatment of diseases characterised by excessive apoptosis should be evaluated and developed. To pursue this goal, we used an 
a

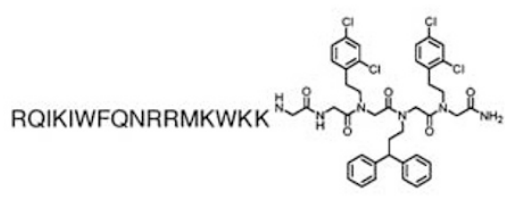

Penetratin-GG-peptoid 1

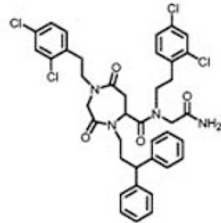

Cyclo-peptoid 1

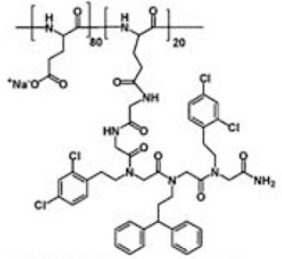

PGA-GG-peptoid 1

b
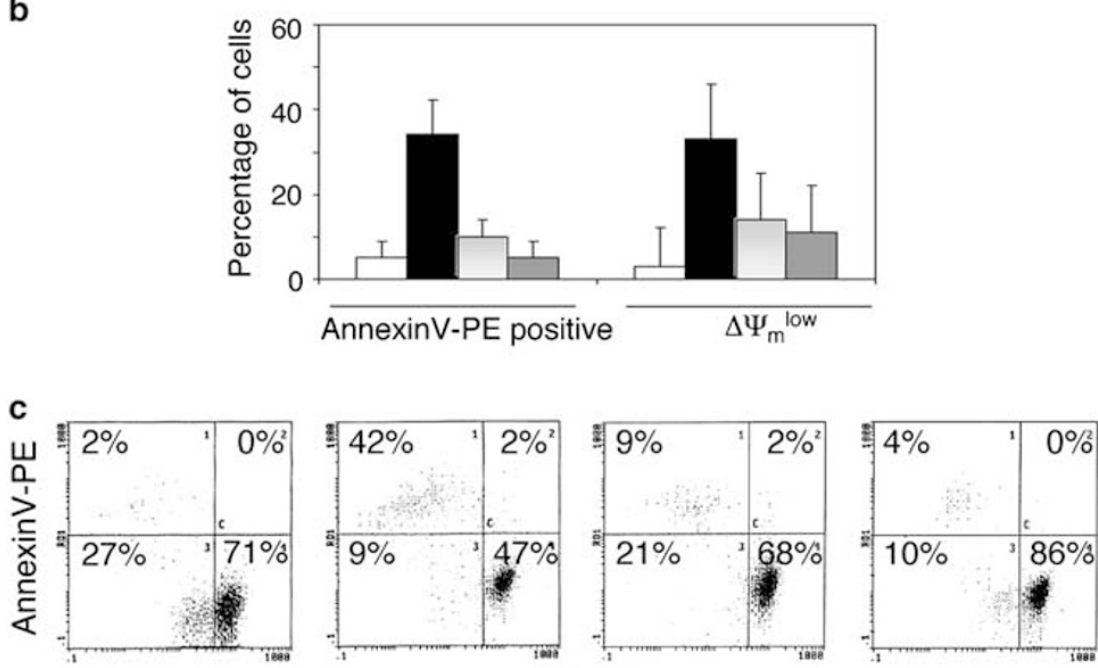

$\mathrm{DiOC}_{6}(3)$

d

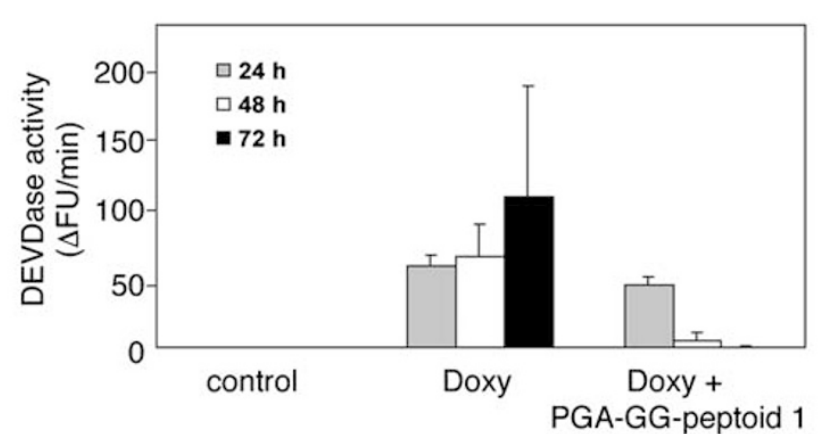

Figure 5 Peptoid 1 analogues reduce doxorubicin-induced apoptosis in U937 cells and Bax-induced apoptosis in Saos-2 cells. (a) Structure of penetratin-GG-peptoid 1, cyclo-peptoid 1 and PGA-GG-peptoid 1. The penetratin- and PGA-GG-peptoid 1 were synthesised (see Materials and Methods section) by covalently attaching the penetratin sequence (one letter code for amino acids) and the poly(L-glutamic acid) (PGA) carrier, respectively, to the peptoid 1 structure flanked by a linker of two glycine residues. (b) U937 cells were cultured in the absence (white bars) or in the presence of either doxorubicin $0.5 \mu \mathrm{M}$ (black bars), or doxorubicin $0.5 \mu \mathrm{M}$ plus penetratin-GGpeptoid 1, $5 \mu \mathrm{M}$ (soft grey bars), or doxorubicin $0.5 \mu \mathrm{M}$ plus cyclo-peptoid 1a, $5 \mu \mathrm{M}$ (dark grey bars). Apoptosis was evaluated by flow cytometry as the percentage of cells with exposed phosphatidylserine (annexinV-PE positive) and low $\Delta \Psi_{\mathrm{m}}\left(\Delta \Psi_{\mathrm{m}}^{\text {low }}\right)$. (c) Flow cytometric analysis of PS exposure and $\Delta \Psi_{\mathrm{m}}$ of cells treated with the same procedures as in (b). From the left, control, doxorubicin, doxorubicin plus penetratin-GG-peptoid 1, and doxorubicin plus cyclo-peptoid 1a, respectively. Numbers refer to the percentages of cells in the different regions. (d) Saos-2 cells were cultured in the absence (control) or in the presence of doxycycline $2 \mu \mathrm{M}$ (Doxy) or doxycycline $2 \mu \mathrm{M}$ plus PGA-GG-peptoid $120 \mu \mathrm{M}$ (Doxy + PGA-GG-peptoid 1) at incubation times of $24 \mathrm{~h}$ (grey bars), $48 \mathrm{~h}$ (white bars) and $72 \mathrm{~h}$ (black bars). Caspase 3 activity in Saos-2 cell extracts was measured by the fluorimetric DEVDase assay

in vitro reconstituted apoptosome assay suitable to screen chemical libraries composed either of mixtures or of individual compounds. A relevant application of this assay is the identification of a novel class of trialkylglycine-based molecules that inhibit the apoptosome-dependent activation of caspase-9. Oligomers of $N$-substituted glycines provide a class of small, non-natural molecules that are proteolytically stable and have potent biological activities. ${ }^{38}$ The newly identified lead compound peptoid 1a binds reversibly to
Apaf-1 in a cytochrome $c$ noncompetitive manner and precludes the recruitment and activation of procaspase-9. In fact, here we show that rApaf- 1 in the absence of dATP and cytochrome $c$ behaves in a size exclusion column as a $140 \mathrm{kDa}$ protein that when incorporated to cellular extracts containing caspases (FT extract) is able to activate these enzymes (see Materials and Methods section and Supplementary information). Moreover, we obtain a functional $(\sim 700 \mathrm{kDa})$ apoptosome when rApaf-1 is subjected to size 
exclusion chromatography in the presence of the FT extract and the enzymatic activity is inhibited when such a fraction eluted from the column is treated with peptoid 1a (Figure 3D). However, when rApaf-1 in the presence of both the FT extract and peptoid $1 \mathbf{a}$ is subjected to size exclusion chromatography, the protein elutes as a major peak centred at elution volumes that correspond to a larger complex that could be related with the previously reported ${ }^{30} \sim 1.4 \mathrm{kDa}$ less active apoptosome complex (Figure 3D). It is tempting to speculate that peptoid 1a promotes the oligomerisation event by its binding to rApaf-1 and induction of an inappropriate for correct oligomerisation conformation on the protein. If this is true, it is possible that Apaf- 1 could have an allosteric site that could bind to still undiscovered intrinsic inhibitors that could participate in the physiological inactivation of the apoptosis program in certain cells.

Initial structure-activity relationship studies showed that a peptoid 1a analogue that was synthesised without one of the dichlorophenethyl moieties lost the ability to inhibit the apoptosome activity. Noticeably, Nguyen and Wells ${ }^{16}$ have reported recently the identification of small molecules bearing a dichlorobenzylamino moiety as direct activators of apoptosis and promoters of cytostatic and cytotoxic effects on a variety of cancer cell lines. Compounds from an indolonone series in which the amino function was linked to a carbonyl group displayed the most potent activity. Likewise, a halophenyl moiety, in this case bearing a trifluoromethyl group, is also present in the diarylurea derivatives identified recently by Lademann et al. ${ }^{15}$ as inhibitors of the formation of the apoptosome complex. Acylated amino residues located close to the halophenyl group were also present in these compounds. Taken together with our results, it appears that a haloaryl moiety linked directly or through a short alkyl spacer to an acylated amino group can exert an interaction with the apoptosome complex. However, those structural complementary features that confer an activation effect or an inhibitory activity on the formation of the apoptosome complex and/or switch on of the apoptosis machinery remain still to be elucidated.

The parent peptoid 1 exhibit low membrane permeability, thus exhibiting very modest efficacy arresting apoptosis in cellular models. To overcome this handicap, we designed more cell permeable molecules and demonstrated efficacy in three independent cell models. Treatment of doxorubicinchallenged U937 cells with selected membrane-permeable analogues of peptoid $\mathbf{1}$ decreases phenotypic markers of apoptosis. When the Apaf-1 inhibitor was supplied through lysosomotropic delivery, it protected Saos-2 cells from apoptosis induced by overexpression of the proapoptotic protein Bax, specific for the mitochondrial pathway. Moreover, these inhibitors could not prevent cell death activated by TNF $\alpha$ in a mouse embryonic fibroblast model, indicating that only apoptosis induced through the mitochondrial pathway can be blocked by peptoid 1. In summary, although there are questions that still need to be addressed, a new structural class of apoptosome inhibitors has been designed based on oligomers of $\mathrm{N}$-alkylglycines. The discovery of this new class of inhibitors provides a new medicinal chemistry tool in the search for lead compounds that could be developed for the treatment of apoptosis-mediated diseases. Furthermore, intracellular protein-protein interactions constitute major control points in many signalling pathways, yet have frequently proven a difficult target for small molecule chemistry, often reflecting a protein interface that is extensive, shallow, and hydrophobic. Such endogenous control points are typically regulated by other protein domains or their modifications. Approaches such as the one presented here reinforce that synthetic molecule provide an alternative strategy to probe protein-protein interactions and manipulate biological pathways.

\section{Materials and Methods}

\section{Chemistry}

The library and individual $\mathrm{N}$-alkylglycine trimers, pentamers, fluorescent and cyclic derivatives were synthesised following procedures previously described. ${ }^{19}$ For the case of peptoid $1 \mathbf{b}$, introduction of the third $\mathrm{N}$-alkylglycine residue was carried out by using the pre-formed $\mathrm{N}$-(2,4dichlorophenethyl)glycinamide. By this procedure, the formation of cyclic sideproducts promoted by the presence of a tertiary amino moiety in the $\mathrm{N}$-alkylglycine present in the second position of the pentamer ${ }^{19}$ was circumvented. The hybrid penetratin-GG-peptoid 1 molecule was prepared by Fmoc-based solid phase synthesis on a 433A Applied Biosystems Peptide synthesiser where the preassembled peptoidyl 1-resin was loaded. Peptoids purity was confirmed by HPLC and mass spectrometry. The HPLC analyses were carried out using a Kromasil 100 C8 $(15 \times 0.46 \mathrm{~cm}, 5 \mu \mathrm{m})$ column, with $\mathrm{CH}_{3} \mathrm{CN} / \mathrm{H}_{2} \mathrm{O}$ mixtures containing $0.1 \%$ TFA at $1 \mathrm{ml} / \mathrm{min}$ as mobile phase and monitoring at $220 \mathrm{~nm}$ and showed purities over $80 \%$ for all the individual peptoids. High-resolution mass spectra (HRMS) were carried out at the Mass Spectrometry Service of the University of Santiago de Compostela (Spain). To synthesise PGAGG-peptoid 1 conjugate, poly(L-glutamic acid) sodium salt with a molecular weight $\left(M_{\mathrm{w}}\right)$ of approx. $20000 \mathrm{Da}$ (Sigma) was used as carrier. $\mathrm{NH}_{2}$-GG-peptoid 1 was conjugated to the PGA carrier by a carbodiimidemediated coupling approach. To stop the reaction, the mixture was poured into chloroform. The resulting precipitate was collected and dried in vacuum. The sodium salt of PGA-peptoid conjugate was obtained by dissolving the product in $1.0 \mathrm{M} \mathrm{NaHCO}_{3}$. The aqueous solution of PGApeptoid conjugate was dialysed against distilled water $\left(M_{\mathrm{W}}\right.$ CO 12000) and lyophilised to yield the desired conjugated (98\% yield) with a $22 \%$ (w/w) peptoid loading as determined by UV.

\section{Production and purification of recombinant Apaf 1-XL in a baculovirus expression system}

Recombinant Apaf-1-XL (rApaf-1) was obtained as described. ${ }^{3}$ Briefly, Apaf-1 cDNA (kindly provided by G Nuñez, Michigan University) was subcloned into pFastBac I vector with a C-terminal 9-His-tag. The expression plasmid was transformed into $\mathrm{DH} 10 \mathrm{Bac}$ Escherichia coli cells. The recombinant bacmids were purified as recommended by the manufacturer (Invitrogen) and used to transfect SF9 insect cells. The virus stock was amplified and used to infect suspension cultures. The infected cells were harvested after $40 \mathrm{~h}$, washed in cold phosphatebuffered saline (PBS), and resuspended in 5 volumes of buffer $A$ (20 mM HEPES-KOH pH 8.0, $10 \mathrm{mM} \mathrm{KCl,} 1.5 \mathrm{mM} \mathrm{MgCl}, 1 \mathrm{mM}$ DTT (dithiothreitol)) supplemented with Complete Protease Inhibitor Cocktail (Roche). Cells were lysed with a dounce homogeniser and recombinant protein was purified using a Ni-NTA $\left(\mathrm{Ni}^{2+}\right.$-nitrilotriacetate)-agarose column. The eluted recombinant rApaf-1 protein was concentrated by 
filtration using Microcon YM10 membranes (Millipore), dialysed against buffer $A$ and stored in multiple aliquots containing $20 \%$ glycerol at $-80^{\circ} \mathrm{C}$ after being snap frozen in liquid nitrogen. Before the apoptosome in vitro reconstitution assays, rApaf-1 was further analysed by size exclusion chromatography. UV absorption (at $280 \mathrm{~nm}$ ) showed that protein eluted as a major single peak with an apparent molecular weight of approximately $150 \mathrm{kDa}$, consistent with the size of monomeric Apaf-1..$^{39,40}$ We then tested whether fractions from size exclusion chromatography activated caspases by mixing them with $\mathrm{FT}$, a fraction from 293 cell extracts that lacks Apaf- 1 but contains caspase- $9,-3$ and cytochrome $c{ }^{14,41}$ Caspase activation was triggered by a fraction corresponding to $150 \mathrm{kDa}$. Finally, the presence of Apaf-1 in this fraction was confirmed by immunoblot (see Supplementary information).

\section{In vitro apoptosome assay}

Assays were performed incubating $200 \mathrm{ng}$ of purified rApaf- 1 with $30 \mathrm{ng}$ horse heart cytochrome $c$ (Sigma-Aldrich), $3 \mu \mathrm{l}$ of in vitro translated $\left[{ }^{35} \mathrm{~S}\right]$ Met procaspase- 9 (obtained using the TNT kit from Promega), $0.1 \mathrm{mM}$ dATP, in a total volume of $20 \mu$ l of buffer A ( $20 \mathrm{mM} \mathrm{HEPES}-\mathrm{KOH}$, $\mathrm{pH} 7.5,10 \mathrm{mM} \mathrm{KCl}, 1.5 \mathrm{mM} \mathrm{MgCl}_{2}, 1 \mathrm{mM} \mathrm{NaEDTA}, 1 \mathrm{mM} \mathrm{NaEGTA}$, $1 \mathrm{mM}$ DTT, $0.1 \mathrm{mM}$ PMSF). Samples were incubated at $30^{\circ} \mathrm{C}$ for $1 \mathrm{~h}$ and proteins resolved by SDS-PAGE. Gels were dried and caspase- 9 processing detected by phosphorimaging in a Fujifilm FLA-3000 Phosphorimager. For the screening of the combinatorial library (see Supplementary information) and for the final defined peptoids, each peptoid mixture (at a final concentration of $0.2 \mathrm{mg} / \mathrm{ml}$ ) or defined peptoid (at concentrations detailed in the text and figures) were preincubated with rApaf- 1 for $30 \mathrm{~min}$ at $30^{\circ} \mathrm{C}$ in a total volume of $16 \mu$ before adding cytochrome $c$, and in vitro translated $\left[{ }^{35}\right.$ S]Met procaspase- 9 and assessing caspase- 9 processing as described above.

\section{Cell culture and extract preparation}

293 cells, a human embryonic kidney cell line, were cultured in Dulbecco's modified Eagle's medium, $10 \%$ fetal bovine serum, in $10 \% \mathrm{CO}_{2}$. Cells were seeded in $15 \mathrm{~cm}$ plates at $1-2 \times 10^{6}$ cells per plate and harvested when confluent (approximately $10^{7}$ cells per plate). S-100 extracts from 293 cells were prepared from $2 \times 10^{8}$ cells and fractionated essentially as described. ${ }^{41}$ Briefly, fractionation of extracts was carried out by ionexchange chromatography using a Mono $Q$ column (Amersham Pharmacia Biotech). An S-100 extract was separated into three fractions (F1, F2 and FT) and its composition was confirmed by immunoblot. F1 ( $5 \mu \mathrm{g}$ of protein $/ \mu \mathrm{l}$ ) contained Apaf-1 and FT ( $30 \mu \mathrm{g}$ of protein $/ \mu \mathrm{l})$ contained caspases- 3 and -9 , and cytochrome $c$. None of these fractions had caspase activity but a combination of $\mathrm{F} 1$ and $\mathrm{FT}$ reconstituted caspase activation. The U937 human histiocytic lymphoma cell line was obtained from the American Type Culture Collection (Rockville, MD, USA). The cells were grown in suspension in RPMI 1640 medium (Cellgro; Fischer Scientific) supplemented with 10\% fetal-calf serum (FCS; Omega Scientific), penicillin $(100 \mu \mathrm{g} / \mathrm{ml})$, streptomycin $(100 \mu \mathrm{g} / \mathrm{ml})$, and $2 \mathrm{mM} \mathrm{L-}$ glutamine (Gibco, UK). Cells were maintained at $37^{\circ} \mathrm{C}$ in an atmosphere of $5 \%$ carbon dioxide and $95 \%$ air and underwent passage twice weekly. The Saos-2 cell line and MEFs were kindly provided by Karin Vousden (Cancer Research UK, Glasgow). The cells were grown in Dulbecco's modified Eagle's medium (GIBCO) supplemented with 10\% FCS (GIBCO). Cells were maintained at $37^{\circ} \mathrm{C}$ in an atmosphere of $5 \%$ carbon dioxide and 95\% air.

Saos-2 extracts were prepared from cells seeded in $3.5 \mathrm{~cm}$ plates at $1 \times 10^{5}$ cells per plate. After different treatments, cells were harvested and the pellets resuspended in $30 \mu \mathrm{l}$ of extraction buffer ( $50 \mathrm{mM}$ PIPES, $50 \mathrm{mM} \mathrm{KCl}, 5 \mathrm{mM}$ EGTA, $2 \mathrm{mM} \mathrm{MgCl}$, $2 \mathrm{mM}$ DTT supplemented with protease inhibitor cocktail from Sigma) and kept on ice $5 \mathrm{~min}$. After three rounds of freeze and thaw, cell lysates were centrifuged at 14000 r.p.m. $5 \mathrm{~min}$ and supernatants were collected. Quantification of total protein concentration from these cell extracts was performed using the bicinchoninic acid method (Pierce).

\section{Cell-free caspase activation assays (DEVDase activity)}

rApaf-1 (5-10 ng) was added to FT fraction (5 $\mu$ l) and incubated with $1 \mathrm{mM}$ ATP or dATP at $37^{\circ} \mathrm{C}$, for $30 \mathrm{~min}$. Then, a $3 \mu$ laliquot was mixed with $200 \mu$ l of caspases assay buffer (PBS, 10\% glycerol, $0.1 \mathrm{mM}$ EDTA, $2 \mathrm{mM}$ DTT) containing $20 \mu \mathrm{M}$ Ac-DEVD-afc (Biomol). Caspase activity was continuously monitored following the release of fluorescent afc at $30^{\circ} \mathrm{C}$ using a Cytofluor 4000 fluorimeter $\left(\lambda_{\mathrm{exc}}=400 \mathrm{~nm} ; \lambda_{\mathrm{em}}=508 \mathrm{~nm}\right.$ ). DEVDase activity was expressed as either as increase of relative fluorescence units per min $(\Delta \mathrm{FU} / \mathrm{min})$ or as percentage of the initial fluorescence signal value obtained in the absence of inhibitor when the inhibitory activity of compounds was evaluated.

\section{MTT cell viability assays}

An MTT cell viability assay was used to measure cell recovery of Saos-2 human osteosarcoma cells. Saos-2 cells were seeded in sterile 96-well microtitre plates at a seeding density of $10^{5} \mathrm{cell} / \mathrm{s} / \mathrm{ml}$ and allow settling for $24 \mathrm{~h}$. Doxycycline $(2 \mu \mathrm{g} / \mathrm{ml}$ in PBS$)$ was then added and after $30 \mathrm{~min}$ peptoid 1 analogues ( $0.2 \mu \mathrm{m}$ filter sterilised) were also added to give a final concentration of $5-20 \mu \mathrm{M}$ drug-equiv. After $19 \mathrm{~h}, 43$ and a $67 \mathrm{~h}$ incubation times, MTT ( $20 \mu \mathrm{l}$ of a $5 \mathrm{mg} / \mathrm{ml}$ solution) was added to each well, and the cells were further incubated for $5 \mathrm{~h}$. After removal of the medium, the precipitated formazan crystals were dissolved in optical grade DMSO $(100 \mu \mathrm{l})$, and the plates were read at $570 \mathrm{~nm}$ using a Wallac 1420 Workstation

\section{Size exclusion chromatography}

rApaf-1 $(5 \mu \mathrm{g})$ was incubated in the absence or in the presence of cytochrome $c(1 \mu \mathrm{M})$ at $30^{\circ} \mathrm{C}$ for $15 \mathrm{~min}$ with ATP $(1 \mathrm{mM})$ in buffer $\mathrm{A}$, loaded onto a Superose-6 High Resolution (H-R) column (Amersham Pharmacia Biotech) and eluted in $50 \mathrm{mM} \mathrm{NaCl}$, HEPES-KOH $20 \mathrm{mM} \mathrm{pH}$ $7.0,0.1 \%$ Chaps, $5 \%$ sucrose, $5 \mathrm{mM} \mathrm{DTT}$, flow rate $0.5 \mathrm{ml} / \mathrm{min}$. Fractions $(0.5 \mathrm{ml})$ were collected and to determine which fractions activated caspases, $4 \mu \mathrm{l}$ of each fraction was mixed with FT $(5 \mu \mathrm{l})$ and incubated at $37^{\circ} \mathrm{C}$ for $30 \mathrm{~min}$, after that time caspase activity was assessed as described above.

\section{Pulldown assays}

In total, $250 \mathrm{ng}$ of rApaf-1 were incubated with peptoid 1a or buffer A for $30 \mathrm{~min}$ at $30^{\circ} \mathrm{C}$ in a total reaction volume of $20 \mu \mathrm{l}$. Then $1 \mathrm{mM} \mathrm{ATP}, 1 \mu \mathrm{M}$ cytochrome $c$ and a $5 \mu \mathrm{l}$ aliquot of an in vitro translated reaction of noncleavable $\left[{ }^{35} \mathrm{~S}\right]$ Met procaspase-9 (procaspase-9 mutant D315/ $330 \mathrm{~A}){ }^{26}$ were added and further incubated for $30 \mathrm{~min}$ at $37^{\circ} \mathrm{C}$. The reaction was diluted $1: 10$ in cold buffer $A$ and $20 \mu l$ of $\mathrm{Ni}^{2+}$-NTA agarose beads were used to pull down rApaf- 1 complexes for $1 \mathrm{~h}$ at $4^{\circ} \mathrm{C}$. After three washes with cold buffer $A$, samples were resolved by SDS-PAGE and caspase- 9 detected by autoradiography. 


\section{Fluorescence polarisation assay}

Fluorescence polarisation measurements were made in a Victor2V 1420 Multilabel HTS Counter. A $60 \mathrm{nM}$ solution of $5^{\prime}-6^{\prime}$ carboxyfluoresceinlabelled peptoid 1a (named peptoid f1a; $\lambda_{\text {exc }}=480 \mathrm{~nm} ; \lambda_{\text {em }}=535 \mathrm{~nm}$ ) in buffer A (total reaction volume was $200 \mu \mathrm{l}$ ) was titrated with concentrated protein solutions. Data were recorded by using a Wallac 1420 Workstation software. The $K_{d}$ values were calculated using a two state model.

\section{Evaluation of cell toxicity and flow cytometry analysis}

U937 cells were treated in 24-well plates ( $1 \mathrm{ml} /$ well) for the times indicated, with $0.5 \mu \mathrm{M}$ doxorubicin. In apoptosis inhibition assays, cells were then treated with $5 \mu \mathrm{M}$ penetratin-GG-peptoid 1 or cyclo-peptoid 1a. Apoptosis was analysed by flow cytometry by determining the changes in cell forward/side scatter and through the simultaneous determination of phosphatidylserine (PS) exposure and mitochondrial membrane potential $\left(\Delta \Psi_{\mathrm{m}}\right)$ loss with annexin V-PE (Caltag) and DiOC6(3) (Molecular Probes), respectively. ${ }^{42}$

\section{Acknowledgements}

This work was supported by grants from Spanish Ministry of Science and Techonology (SAF2001-2811, SAF2001-2286 and BIO2004-998), Fundación Areces and Fundación Valenciana de Investigaciones Biomédicas. We thank Alicia García (Centro de Investigación Príncipe Felipe), and Adelina Calviño (IIQAB) for technical assistance; Dr. Gabriel Nuñez and Dr. Vishva Dixit for providing cDNAs of Apaf-1-XL and procaspase 9, respectively. We would like also thank to Dr. Patrice $X$. Petit for critical reading of the manuscript and Dr. Isabel Marzo for help with the experiments with U937 cells.

\section{References}

1. Reed JC (2001) Apoptosis-regulating proteins as targets for drug discovery. Trends Mol. Med. 7: 314-319

2. Strasser A, O'Connor L and Dixit VM (2000) Apoptosis signaling. Annu. Rev. Biochem. 69: 217-245

3. Zou H, Li Y, Liu X and Wang X (1999) An APAF-1.cytochrome c multimeric complex is a functional apoptosome that activates procaspase-9. J. Biol. Chem. 274: 11549-11556

4. Chai J, Du C, Wu JW, Kyin S, Wang X and Shi Y (2000) Structural and biochemical basis of apoptotic activation by Smac/DIABLO. Nature 406: 855-862

5. Li P, Nijhawan D, Budihardjo I, Srinivasula SM, Ahmad M, Alnemri ES and Wang X (1997) Cytochrome $c$ and dATP-dependent formation of Apaf-1/ caspase-9 complex initiates an apoptotic protease cascade. Cell 91: 479-489

6. Acehan D, Jiang X, Morgan DG, Heuser JE, Wang X and Akey CW (2002) Three-dimensional structure of the apoptosome: implications for assembly, procaspase-9 binding, and activation. Mol. Cell 9: 423-432

7. Rodriguez $\mathrm{J}$ and Lazebnik $\mathrm{Y}$ (1999) Caspase-9 and APAF-1 form an active holoenzyme. Genes Dev. 13: 3179-3184

8. Srinivasula SM, Ahmad M, Fernandes-Alnemri T and Alnemri ES (1998) Autoactivation of procaspase-9 by Apaf-1-mediated oligomerization. Mol. Cell 1: $949-957$

9. Scott CW, Sobotka-Briner C, Wilkins DE, Jacobs RT, Folmer JJ, Frazee WJ, Bhat RV, Ghanekar SV and Aharony D (2003) Novel small molecule inhibitors of caspase-3 block cellular and biochemical features of apoptosis. J. Pharmacol. Exp. Ther. 304: 433-440

10. Garcia-Calvo M, Peterson EP, Leiting B, Ruel R, Nicholson DW and Thornberry NA (1998) Inhibition of human caspases by peptide-based and macromolecular inhibitors. J. Biol. Chem. 273: 32608-32613

11. Zhu S, Stavrovskaya IG, Drozda M, Kim BY, Ona V, Li M, Sarang S, Liu AS, Hartley DM, Wu du C, Gullans S, Ferrante RJ, Przedborski S, Kristal BS and
Friedlander RM (2002) Minocycline inhibits cytochrome $\mathrm{c}$ release and delays progression of amyotrophic lateral sclerosis in mice. Nature 417: 74-78

12. Wang X, Zhu S, Drozda M, Zhang W, Stavrovskaya IG, Cattaneo E, Ferrante RJ, Kristal BS, Friedlander RM, Kim BY, Ona V, Li M, Sarang S, Liu AS, Hartley DM, Wu du C, Gullans S and Przedborski S (2003) Minocycline inhibits caspase-independent and -dependent mitochondrial cell death pathways in models of Huntington's disease. Proc. Natl. Acad. Sci. USA 100: 10483-10487

13. Mochizuki H, Hayakawa H, Migita M, Shibata M, Tanaka R, Suzuki A, ShimoNakanishi Y, Urabe T, Yamada M, Tamayose K, Shimada T, Miura M and Mizuno Y (2001) An AAV-derived Apaf-1 dominant negative inhibitor prevents MPTP toxicity as antiapoptotic gene therapy for Parkinson's disease. Proc. Natl. Acad. Sci. USA 98: 10918-10923

14. Martin AG and Fearnhead HO (2002) Apo cytochrome $c$ blocks caspase-9 activation and Bax-induced apoptosis. J. Biol. Chem. 277: 50834-50841

15. Lademann U, Cain K, Gyrd-Hansen M, Brown D, Peters D and Jaattela M (2003) Diarylurea compounds inhibit caspase activation by preventing the formation of the active 700-kilodalton apoptosome complex. Mol. Cell. Biol. 23: 7829-7837

16. Nguyen JT, Wells JA, Lugovskoy AA, Degterev Al, Fahmy AF, Zhou P, Gross JD, Yuan J, Wagner G, Degterev A, Lugovskoy A, Cardone M, Mulley B and Mitchison T (2003) Direct activation of the apoptosis machinery as a mechanism to target cancer cells. Proc. Natl. Acad. Sci. USA 100: 7533-7538

17. Simon RJ, Kania RS, Zuckermann RN, Huebner VD, Jewell DA, Banville $\mathrm{S}, \mathrm{Ng}$ S, Wang L, Rosenberg S, Marlowe CK, Spellmeyer DC, Tan R, Frankel AD, Santi DV, Cohen FE and Bartlett PA (1992) Peptoids: a modular approach to drug discovery. Proc. Natl. Acad. Sci. USA 89: 9367-9371

18. Burkoth TS, Beausoleil E, Kaur S, Tang D, Cohen FE and Zuckermann RN (2002) Toward the synthesis of artificial proteins: the discovery of an amphiphilic helical peptoid assembly. Chem. Biol. 9: 647-654

19. Humet M, Carbonell T, Masip I, Sanchez-Baeza F, Mora P, Canton E, Gobernado M, Abad C, Perez-Paya E and Messeguer A (2003) A positional scanning combinatorial library of peptoids as a source of biological active molecules: identification of antimicrobials. J. Comb. Chem. 5: 597-605

20. Garcia-Martinez C, Humet M, Planells-Cases R, Gomis A, Caprini M, Viana F, De La Pena E, Sanchez-Baeza F, Carbonell T, De Felipe C, Perez-Paya E, Belmonte C, Messeguer A and Ferrer-Montiel A (2002) Attenuation of thermal nociception and hyperalgesia by VR1 blockers. Proc. Natl. Acad. Sci. USA 99: 2374-2379

21. Planells-Cases R, Montoliu C, Humet M, Fernandez AM, Garcia-Martinez C, Valera E, Merino JM, Perez-Paya E, Messeguer A, Felipo V and Ferrer-Montiel A (2002) A novel $N$-methyl-D-aspartate receptor open channel blocker with in vivo neuroprotectant activity. J. Pharmacol. Exp. Ther. 302: 163-173

22. Montoliu C, Humet M, Canales JJ, Burda J, Planells-Cases R, Sanchez-Baeza F, Carbonell T, Perez-Paya E, Messeguer A, Ferrer-Montiel A and Felipo V (2002) Prevention of in vivo excitotoxicity by a family of trialkylglycines, a novel class of neuroprotectants. J. Pharmacol. Exp. Ther. 301: 29-36

23. Masip I, Cortés N, Abad MJ, Guardiola M, Pérez-Payá E, Ferragut J, FerrerMontiel A and Messeguer A (2005) Design and synthesis of an optimized positional scanning library of peptoids: identification of novel multidrug resistance reversal agents. Biorg. Med. Chem. 13: 1923-1929

24. Gonzalez-Navarro H, Mora P, Pastor M, Serrano L, Mingarro I and Perez-Paya E (2000) Identification of peptides that neutralize bacterial endotoxins using beta-hairpin conformationally restricted libraries. Mol. Divers 5: 117-126

25. Pastor MT, Lopez de la Paz M, Lacroix E, Serrano L and Perez-Paya E (2002) Combinatorial approaches: a new tool to search for highly structured betahairpin peptides. Proc. Natl. Acad. Sci. USA 99: 614-619

26. Bratton SB, Walker G, Roberts DL, Cain K and Cohen GM (2001) Caspase-3 cleaves Apaf-1 into an approximately $30 \mathrm{kDa}$ fragment that associates with an inappropriately oligomerized and biologically inactive approximately $1.4 \mathrm{MDa}$ apoptosome complex. Cell Death Differ. 8: 425-433

27. Qin H, Srinivasula SM, Wu G, Fernandes-Alnemri T, Alnemri ES and Shi Y (1999) Structural basis of procaspase-9 recruitment by the apoptotic proteaseactivating factor 1. Nature 399: 549-557

28. Hill MM, Adrain C, Duriez PJ, Creagh EM and Martin SJ (2004) Analysis of the composition, assembly kinetics and activity of native Apaf-1 apoptosomes. EMBO J. 23: 2134-2145

29. Cain K, Brown DG, Langlais C and Cohen GM (1999) Caspase activation involves the formation of the aposome, a large (approximately $700 \mathrm{kDa}$ ) caspase-activating complex. J. Biol. Chem. 274: 22686-22692 
30. Cain K, Bratton SB, Langlais C, Walker G, Brown DG, Sun XM and Cohen GM (2000) Apaf-1 oligomerizes into biologically active approximately $700-\mathrm{kDa}$ and inactive approximately 1.4-MDa apoptosome complexes. J. Biol. Chem. 275: 6067-6070

31. Fearnhead HO (2001) Cell-free systems to study apoptosis. Methods Cell Biol. 66: $167-185$

32. Thoren PE, Persson D, Esbjorner EK, Goksor M, Lincoln P and Norden B (2004) Membrane binding and translocation of cell-penetrating peptides. Biochemistry 43: 3471-3489

33. Thoren PE, Persson D, Karlsson M and Norden B (2000) The antennapedia peptide penetratin translocates across lipid bilayers - the first direct observation. FEBS Lett. 482: 265-268

34. Duncan R (2003) The dawning era of polymer therapeutics. Nat. Rev. Drug Discov. 2: $347-360$

35. Mendichi R, Rizzo V, Gigli M and Schieroni AG (2002) Fractionation and characterization of a conjugate between a polymeric drug-carrier and the antitumor drug camptothecin. Bioconjug. Chem. 13: 1253-1258

36. Bouillet P and Strasser A (2002) BH3-only proteins - evolutionarily conserved proapoptotic Bcl-2 family members essential for initiating programmed cell death. J. Cell Sci. 115: 1567-1574
37. Lee D, Long SA, Murray JH, Adams JL, Nuttall ME, Nadeau DP, Kikly K, Winkler JD, Sung CM, Ryan MD, Levy MA, Keller PM and DeWolf Jr WE (2001) Potent and selective nonpeptide inhibitors of caspases 3 and 7 . J. Med. Chem. 44: $2015-2026$

38. Ostergaard S and Holm A (1997) Peptomers: a versatile approach for the preparation of diverse combinatorial peptidomimetic bead libraries. Mol. Divers 3: $17-27$

39. Zou H, Henzel WJ, Liu X, Lutschg A and Wang X (1997) Apaf-1, a human protein homologous to $C$. elegans CED-4, participates in cytochrome $C$ dependent activation of caspase-3. Cell 90: 405-413

40. Zou H, Yang R, Hao J, Wang J, Sun C, Fesik SW, Wu JC, Tomaselli KJ and Armstrong RC (2003) Regulation of the Apaf- $1 /$ caspase- 9 apoptosome by caspase-3 and XIAP. J. Biol. Chem. 278: 8091-8098

41. Fearnhead HO, Rodriguez J, Govek EE, Guo W, Kobayashi R, Hannon G and Lazebnik YA (1998) Oncogene-dependent apoptosis is mediated by caspase-9. Proc. Natl. Acad. Sci. USA 95: 13664-13669

42. Marzo I, Perez-Galan P, Giraldo P, Lopez-Royuela N, Gomez-Benito M, Larrad L, Lasierra P, Rubio-Felix D, Anel A and Naval J (2004) Farnesyltransferase inhibitor BMS-214662 induces apoptosis in B-cell chronic lymphocytic leukemia cells. Leukemia 18: 1599-1604

Supplementary Information accompanies the paper on Cell Death and Differentiation website (http://www.nature.com/cdd) 